\title{
Comparative Study of Bioactive Components and Quality from Juices of Different Mandarins: Discriminant Multivariate Analysis of Their Primary and Secondary Metabolites
}

\author{
Almudena Bermejo ${ }^{*}$, José L. Pardo' Julia Morales ${ }^{1}$, Antonio Cano ${ }^{2}$ \\ ${ }^{1}$ Centro de Citricultura y Producción Vegetal, Instituto Valenciano de Investigaciones Agrarias, Valencia, Spain \\ ${ }^{2}$ Departamento de Biología Vegetal (Fisiología Vegetal), Facultad de Biología, Universidad de Murcia, Campus \\ de Espinardo, Murcia, Spain \\ Email:"Bermejo_alm@gva.es
}

Received 17 May 2016; accepted 10 June 2016; published 13 June 2016

Copyright (C 2016 by authors and Scientific Research Publishing Inc.

This work is licensed under the Creative Commons Attribution International License (CC BY).

http://creativecommons.org/licenses/by/4.0/

(c) () Open Access

\section{Abstract}

A comparative study of the primary and secondary metabolites of the juice of several mandarin cultivars with different pollination, seed production and parthenocarpic abilities was carried out, and the antioxidant capacity of the hydrophilic fraction was measured. Correlation by a Principal Component Analysis and a Cluster Analysis was used. By a multivariate analysis, the $\mathbf{1 5}$ citrus cultivars were clustered into four groups consistently with citrus types. The presented data are an important factor for choosing varieties with high potential as a nutraceutical source. These aspects are necessary as consumers demand prevention of health problems through nutrition and certain fruit quality traits, including fruit size, internal quality, good rind color and easy peeling.

\section{Keywords}

Antioxidant Capacity, Carotenoids, Citrus, Flavonoids, Organic Acids, Sugars, Vitamin C

\section{Introduction}

Several studies have evidenced the importance of citrus as a health benefit that promotes fruit because of its high

*Corresponding author.

How to cite this paper: Bermejo, A., Pardo, J.L., Morales, J. and Cano, A. (2016) Comparative Study of Bioactive Components and Quality from Juices of Different Mandarins: Discriminant Multivariate Analysis of Their Primary and Secondary Metabolites. Agricultural Sciences, 7, 341-351. http://dx.doi.org/10.4236/as.2016.76035 
content in nutrients and non nutrient phytochemicals, which are important for human nutrition since they possess antioxidant properties [1] [2]. The antioxidant and antiradical activity of citrus fruit is due mainly to not only the hydrosoluble fraction that contains vitamin $\mathrm{C}$ and phenolic compounds (as flavonoids), but also to the apolar fraction, including carotenoids, which leads to its protective effects against chronic and degenerative diseases [3] [4]. Citrus fruits are acid fruits as their soluble solids are composed of mainly organic acids and sugars, components which contribute to flavor attributes and largely affect taste characteristics and organoleptic quality [5] [6].

Increased consumption of fruits and vegetables is associated with a lower incidence of cardiovascular disease and fewer risks of certain cancers. Nowadays, prevention of health problems through nutrition is being intensively promoted. Citrus fruits have been consumed for decades thanks to their wide availability and the chemical variability of bioactive compounds, and their relationship with factors, such as genotypic differences, climatic conditions, cultural practices, maturity and harvesting methods, has been reported mainly for commercial varieties. Nogata et al. [7] observed that the flavonoid composition of citrus fruits was approximately the same within each section of Tanaka's system [8]. Others have reported the influence of variety and species on the content of the main antioxidant constituents (vitamin C, flavonoids and carotenoids) in Citrus sp [9]. Lee and Kader [10] observed that vitamin C content in fruits and vegetables can be influenced by various factors, such as genotypic differences, preharvest climatic conditions and cultural practices, maturity and harvesting methods. Albertini et al. [5] observed that the content of organic acids and sugars also may vary according to species, varieties, processing and environmental and horticultural conditions, such as climate, rootstock and irrigation. More recently, Goldenberg et al. [11] [12] conducted a comprehensive analysis of fruit-quality traits with 46 distinct mandarin varieties, which included physical, physiological, nutritional and biochemical and sensory attributes, and observed wide genetic variability among mandarin varieties and natural subgroups. Thus high genetic diversity exists in fruit-quality traits among citrus species and varieties, with vast variation among citrus types and cultivars because of frequent bud mutation, interspecific and intergeneric hybridization, etc. Over the last decade, there has been a continuous rise in the consumption and global marketing of fresh easy-to-peel mandarins, and major achievements have been made in breeding techniques to produce seedless fruits. Seedlessness is a desired trait for consumers, and a requisite for the fresh market is the production of high quality citrus fruits with very few or no seeds [13]. Seedlessness in citrus mandarin cultivars can be caused by many factors (female or male sterility, pollen self-incompatibility, etc.). In recent years, we have made huge efforts to: obtain new high quality late-season mandarins with our breeding program at the IVIA (Instituto Valenciano de Investigaciones Agrarias); produce high quality fruits with very few seeds in open pollination [14]-[16]; observe how seed production capacity affects hormonal status, the activity of the genes that encode for GA-oxidases and the ovary's carbohydrate levels in order to gain insight into the extent to which these factors influence fruit set [17].

The composition of some cultivars from the Mediterranean Area is not fully characterized in the literature. We herein provide comprehensive information about these new mandarins vs. commercial ones (under the same climate and field conditions) to establish differences in the main compounds with nutritional importance to provide new information for the citriculture industry to help choose varieties with high potential as a nutraceutical source. For some samples, these data were documented for the first time. Correlation by a multivariate discriminant analysis done with these compounds was used, including a Principal Component Analysis (PCA) and a Cluster Analysis (CA). In our breeding program, these analysis data are most important for choosing mandarin cultivars with different pollination, seed production and parthenocarpic abilities, and with high potential as a nutraceutical source and for certain fruit quality traits, including fruit size, internal quality, good rind color and easy peeling.

\section{Materials and Methods}

\subsection{Plant Material and Sampling}

Fruits of 15 mandarin cultivars were harvested in the maturity stage at the IVIA (Moncada, Valencia, Spain). Clementines Arrufatina, Fina and Loretina [Citrus clementina Hort. ex Tan.] and hybrids Ellendale (the origin of hybrid Ellendale is unknown) and Fortune [C. reticulata Blanco x C. tangerina Hort. ex Tan.], were sampled from the Field Collection of the Citrus Germoplasm Bank held at the IVIA. The hybrid Murta (pollen sterile and seedless) was previously obtained by gamma irradiation [15] from fertile and pollen self-compatible Murcott (the origin of Murcott is unknown, but is most likely a tangor, which is a cross between a tangerine and a sweet orange). The clementine hybrids [C. clementina Hort. ex Tan. $x$ (C. unshiu Marc. $x$ C. nobilis Lour.)] were 
obtained from the IVIA's breeding program: Moncalina (pollen sterile and seedless) from Moncada (pollen self-incompatible and parthenocarpic) [14]; P512 and F518 from O23 (seedy self-compatible and not parthenocarpic); P223 and F210 from Y25 (seedy self-compatible and parthenocarpic) [16]. The fruit sampling procedure and gamma irradiation method have been widely described elsewhere [14]-[16]. Seed number and pollen germination data have been previously reported, and these cultivars have demonstrated excellent fruit size, internal quality and good rind color, whose ripening period takes place from January to April.

After full fruit development and maturation, all fruits were counted and harvested. Weight, height and diameter were measured for each fruit. Juice was obtained from representative samples taken from trees kept in the IVIA's germoplasm bank in the maturity stage (three trees per cultivar: 18 fruits separated into three replicates) using a Zumonat machine (Somatic-AMD, Spain). They were immediately analyzed for ${ }^{\circ} \mathrm{Bx}$ and for acidity (maturity index have been well-described in other works), and juice yield percentage. After harvest, juice was extracted, filtered and then used fresh or stored at $-80^{\circ} \mathrm{C}$ until analyzed. All the cultivars shared the same microclimatic conditions, soil and cultural practices, thus any differences among cultivars were not influenced by environmental factors or crop techniques.

\subsection{Extraction of Vitamin C and Total Antioxidant Activity (TAA)}

Total vitamin C was extracted according to the method described elsewhere [9], with some modifications to adapt the method to a microliter format [18], using DL-dithiothreitol (DTT) as reducing reagent of dehydroascorbic acid to ascorbic acid (ASC). Briefly, $1 \mathrm{~mL}$ of filtered juice was mixed with $1 \mathrm{~mL}$ of $5 \%$ metaphosphoric acid solution, and then the sample was centrifuged (Eppendorf 5810R centrifuge; Eppendorf Iberica, Madrid, Spain) at $4^{\circ} \mathrm{C}$ for $15 \mathrm{~min}$ at $8000 \times \mathrm{g}$. One $\mathrm{mL}$ of supernatant was mixed with $200 \mu \mathrm{L}$ of DTT (20 $\mathrm{mg} \cdot \mathrm{mL}^{-1}$ ) and left to react for $2 \mathrm{~h}$ in the dark, then filtered through $0.45 \mu \mathrm{m}$ filter. It was analyzed by HPLC-DAD in an Alliance liquid chromatographic system (Waters, Barcelona, Spain) equipped with a 2695 separation module coupled to a 2996 photodiode array detector, and a reverse-phase $\mathrm{C}_{18}$ column with an isocratic mobile phase of methanol: $0.6 \%$ acetic acid (5:95, v/v), as previously described [18]. The Empower 2 software (Waters, Spain) was used for data processing, and quantification was performed at $245 \mathrm{~nm}$ by external standard calibration. Three samples per cultivar were analyzed and all the samples were run in triplicate. Standards were run daily with samples for validation. All the used solvents were of HPLC-grade and ultrapure water (Milli-Q) was used. TAA was measured in glass 96-well reaction plates in a microliter-based format [19] [20]. ABTS (2,2'-azino-bis-3-ethylbenzthiazoline-6-sulphonic acid), $\mathrm{H}_{2} \mathrm{O}_{2}$ (hydrogen peroxide), HRP (horseradish peroxidase type VI) and ascorbic acid (ASC) were obtained from Sigma (Sigma Co., Barcelona, Spain). Absorbance was read by an OASYS UVM 340 microplate reader (MIKRO WIN 2000). Nine replicates were measured per cultivar. The results were compared with a standard curve prepared with different ASC concentrations.

\subsection{Extraction and Analysis of Flavonoids}

The main flavonoids were extracted and determined according to the procedure described elsewhere [21]. Briefly, $1 \mathrm{~mL}$ of filtered juice was mixed with $1 \mathrm{~mL}$ of $\mathrm{DMSO} / \mathrm{MeOH}(1: 1, \mathrm{v} / \mathrm{v})$. Then the sample was centrifuged (Eppendorf 5810R centrifuge; Eppendorf Iberica, Madrid, Spain) at $4^{\circ} \mathrm{C}$ for $15 \mathrm{~min}$ at $8000 \times \mathrm{g}$. The supernatant was filtered through a $0.45 \mu \mathrm{m}$ nylon filter and analyzed by HPLC-DAD and HPLC-MS in a reverse-phase column $\mathrm{C}_{18}$. An analysis was done using an Alliance liquid chromatographic system (Waters, Barcelona, Spain) equipped with a 2695 separation module, coupled to a 2996 photodiode array detector and a ZQ2000 mass detector. A gradient mobile phase that consisted in acetonitrile (solvent A) and $0.6 \%$ acetic acid (solvent B) was used. The flow rate was $1 \mathrm{~mL} \cdot \mathrm{min}^{-1}$ and the injection volume was $10 \mu \mathrm{L}$. The conditions were as follows: initial condition of $10 \%$ A for 2 min which reached $75 \% \mathrm{~A}$ in the next $28 \mathrm{~min}$, and then back to the initial condition and held for $5 \mathrm{~min}$ (total run time $35 \mathrm{~min}$ ). An HPLC-MS analysis was performed and worked under electrospray ion positive conditions. Capillary voltage was $3.50 \mathrm{kV}$, cone voltage was $20 \mathrm{~V}$, source temperature was $100^{\circ} \mathrm{C}$, desolvation temperature was $225^{\circ} \mathrm{C}$, cone gas flow was $70 \mathrm{~L} \cdot \mathrm{hr}^{-1}$ and desolvation gas flow was $500 \mathrm{~L} \cdot \mathrm{hr}^{-1}$. Full data acquisition was performed by scanning 200 to 800 uma in the centroid mode. Compounds were indentified on the basis of comparing their retention times, UV-Vis spectra and mass spectrum data with authentic standards using an external calibration curve. Narirutin was purchased from Extrasynthesis (Genay, France), hesperidin from Sigma (Sigma Co., Barcelona, Spain), and didymin from ChromaDex (Irvine, CA, 
USA). All the solvents used were of HPLC-grade and ultrapure water (Milli-Q) was employed.

\subsection{Extraction and Analysis of Carotenoids}

The extraction method was the same as the previously described procedure [22]. Briefly, $20 \mathrm{~mL}$ of filtered juice were mixed with $10 \mathrm{~mL}$ of ethyl acetate $(0.05 \%$ BHT) and $0.5 \mathrm{~g}$ of basic magnesium carbonate. The sample was centrifuged (Eppendorf 5810R centrifuge; Eppendorf Iberica, Madrid, Spain) at $4^{\circ} \mathrm{C}$ for $15 \mathrm{~min}$ at $8000 \times \mathrm{g}$. The supernatant was collected in a $250 \mathrm{~mL}$ decantation funnel, the pellet was re-extracted with $20 \mathrm{~mL}$ of ethyl acetate $(0.05 \%$ BHT) and the supernatant was transferred to the decantation funnel. The organic phase was washed 3 times with NaCl-saturated water, collected and dried on a bed of anhydrous sodium sulfate. Ethyl acetate was removed in a vacuum rotary evaporator at $40^{\circ} \mathrm{C}$. The residue was dissolved in $5 \mathrm{~mL}$ of ethyl ether and saponified with $2.5 \mathrm{~mL}$ of $20 \% \mathrm{KOH}$ in methanol overnight in the dark. The saponified extract was transferred to a $250 \mathrm{~mL}$ decantation funnel, mixed with $20 \mathrm{~mL}$ of diethyl ether and washed 3 times with $\mathrm{NaCl}$-saturated water. Diethyl ether was collected, dried with anhydrous sodium sulfate and evaporated. Dried samples were dissolved in $1 \mathrm{~mL}$ ethyl acetate and analyzed by HPLC-DAD in a $\mathrm{C}_{30}$ column. The flow rate was $1 \mathrm{~mL} \cdot \mathrm{min}^{-1}$ and the injection volume was $20 \mu \mathrm{L}$. A ternary mobile phase of water (A): methanol (B): methyl-tert-butyl ether (C) was used. The initial conditions were 4\% A, 86\% B and 10\% C held for 10 min, then changed to $4 \%$ A, 10\% B and 90\% C for the next $40 \mathrm{~min}$, and back to the initial conditions and conditioning column for $10 \mathrm{~min}$ : total run time $60 \mathrm{~min}$. Compounds were indentified on the basis of comparing their retention times and absorption spectrum characteristics. Carotenoids were quantified using calibration curves. $\beta$-Cryptoxanthin was obtained from Extrasynthese (Extrasynthesis, Genay, France), and $\beta$-carotene was purchased from Biochemica (Sigma Co., Barcelona, Spain). The vitamin A value was calculated as a retinol equivalent (RE) by the following conversion [9] (only $\beta$-carotene and $\beta$-cryptoxanthin contribute to vitamin A activity) using the Equation (1):

$$
\mathrm{RE}=(\mu \mathrm{g} \text { of } \beta \text {-carotene } / 6)+(\mu \mathrm{g} \text { of other provitamin } \mathrm{A}[\beta \text {-cryptoxanthin }] \text { carotenoid } / 12)
$$

\subsection{Extraction and Analysis of Organic Acids}

The extraction method was the same as the previously described procedure [23]. One $\mathrm{mL}$ of filtered juice was mixed with $1 \mathrm{~mL}$ of $0.1 \% \mathrm{H}_{2} \mathrm{SO}_{4}$ solution, then the sample was centrifuged (Eppendorf 5810R centrifuge; Eppendorf Iberica, Madrid, Spain) at $4^{\circ} \mathrm{C}$ for $15 \mathrm{~min}$ at $8000 \times \mathrm{g}$. The supernatant was filtered through a $0.45 \mu \mathrm{m}$ filter, analyzed by HPLC-DAD and confirmed by HPLC-MS under electrospray ion negative conditions. The Empower 2 software was used for data acquisition. Sample temperature was $5^{\circ} \mathrm{C}$ and column temperature was $35^{\circ} \mathrm{C}$. Capillary voltage was $3.0 \mathrm{kV}$, cone voltage was $23 \mathrm{~V}$, source temperature was $100^{\circ} \mathrm{C}$, desolvation temperature was $200^{\circ} \mathrm{C}$ and desolvation gas flow was $400 \mathrm{~L} \cdot \mathrm{hr}^{-1}$. Full data acquisition was performed by scanning from 100 to 400 uma in the centroid mode. An ICSep ICE-COREGEL 87H3 column (Transgenomic, UK), an ICSep ICE-COREGEL 87H guard kit, and an automatic injector were used for chromatographic separation. The solvent system was an isocratic mobile phase of $0.1 \% \mathrm{H}_{2} \mathrm{SO}_{4}$ solution. The total run time was 20 min at 0.6 $\mathrm{mL} \cdot \mathrm{min}^{-1}$, and the injection volume was $5 \mu \mathrm{L}$. Compounds were identified by comparing their retention times, UV-Vis spectra and mass spectrum data with the corresponding authentic standards. Standards were run daily with the samples for validation and concentrations were determined using an external calibration curve with citric acid, malic acid and succinic acid, all obtained from Sigma (Sigma Co., Barcelona, Spain).

\subsection{Extraction and Analysis of Sugars}

Sugars were extracted as described elsewhere [23]. Two $\mathrm{mL}$ of juice were centrifuged (Eppendorf 5810R centrifuge; Eppendorf Iberica, Madrid, Spain) at $4^{\circ} \mathrm{C}$ for $15 \mathrm{~min}$ at $8000 \times \mathrm{g}$. Samples were filtered through a 0.45 $\mu \mathrm{m}$ nylon filter and analyzed by an HPLC system equipped with a Waters 515 HPLC pump. A Waters 2414 refractive index detector, a 5- $\mu \mathrm{m}$ Tracer Carbohydr column ( $250 \mathrm{~mm} \times 4.5 \mathrm{~mm}$ ) (Teknokroma, Barcelona, Spain), and a $20-\mu \mathrm{L}$ loop Rheodyne injector were used for the sugar analysis. The mobile phase was composed of acetonitrile and water $(75: 25)$ at a flow rate of $1.0 \mathrm{~mL} \cdot \mathrm{min}^{-1}$. Fructose, glucose and sucrose sugars were identified by comparing their retention time with a standard and were quantified using an external calibration curve. The Empower 2 software (Waters, Spain) was used for data processing. Standards were obtained from Sigma (Sigma Co., Barcelona, Spain). The results were expressed as $g \cdot \mathrm{L}^{-1}$. The effectiveness of extractions was ascertained using fucose, a sugar that is absent in the extracts, as an internal standard. 


\subsection{Statistical Analysis}

Statistical analyses were performed with the Statgraphics Plus software package, and analyses of variance (ANOVA) of at least three determinations from independent trees were run, and a Duncan's LSD multiple range test $(p<0.05)$ was done to discriminate among means. For both the Principal Component Analysis (PCA) and Cluster Analysis (CA), the complete dataset, including all the replicates, was considered. FactoMineR (R. R package version 1.28) and Community Ecology Package (R package version 2.2-0) were used [24]-[26].

\section{Results and Discussion}

All the samples studied in this paper were harvested in the maturity stage at the IVIA between October and April, depending on the variety chosen, from the same field and under the same climatic conditions to reduce additional sources of variance. The present paper provides comprehensive information about the chemical constituents, and correlation by a multivariate discriminant analysis from these compounds was used, including PCA and CA. For some samples, these data were documented for the first time, although some quality parameters, including juice yield and maturity index, seed number and pollen germination data, have been well-described in previous works. Fruit weight, size, acidity, maturity index and harvest time (Table 1), as well as chemical and nutritional composition (Table 2 and Table 3), are important factors for evaluating the internal quality of citrus cultivars. It is important to note that among all the studied varieties, clementine mandarins Arrufatina, Fina and Loretina gave the highest maturity index values (from 11.00 to 14.00) in the optimum ripening stage. Some hybrids obtained values below 8.0, and the remaining varieties presented similar values, between 9.0 and 10.0. The percentages of juice yields were around 50\%, although the new varieties obtained from O23 and Y25 obtained values that came close to or were above $60 \%$.

\subsection{Vitamin C and TAA}

Citrus fruits are a well-known nutrient source of vitamin C in dietary intake, this being the major antioxidant compound found in these fruits [2]. Table 2 shows the total vitamin $\mathrm{C}$ content determined by the HPLC method (expressed as $\mathrm{mg} \cdot 100 \mathrm{~mL}^{-1}$ values) and the TAA is expressed as $\mathrm{L}$-ASC equivalents (mg.100 $\mathrm{mL}^{-1}$ ) determined by ABTS method. The total vitamin C levels ranged from 19.57 to $59.30 \mathrm{mg} \cdot 100 \mathrm{~mL}^{-1}$, which is in agreement

Table 1. Fruit quality parameters in mandarins studied ${ }^{1}$.

\begin{tabular}{|c|c|c|c|c|c|}
\hline Names & Weight (g) & Diameter (mm) & Height (mm) & Mat. Index & \% juice \\
\hline Arrufatina & $97.20 \mathrm{~d}$ & 59.93 de & 48.37 de & $12.60 \mathrm{i}$ & $36.80 \mathrm{a}$ \\
\hline Fina & $84.00 \mathrm{~b}$ & $55.30 \mathrm{~b}$ & 48.77 de & $11.70 \mathrm{~h}$ & $39.00 \mathrm{~b}$ \\
\hline Loretina & $74.30 \mathrm{a}$ & 53.33 a & 49.07 de & $10.90 \mathrm{~g}$ & $44.83 \mathrm{c}$ \\
\hline Moncada & $129.75 \mathrm{~g}$ & $67.60 \mathrm{~g}$ & $49.55 \mathrm{e}$ & $10.48 \mathrm{fg}$ & $52.50 \mathrm{e}$ \\
\hline Moncalina & $117.50 \mathrm{f}$ & $66.88 \mathrm{~g}$ & 48.65 de & $10.08 \mathrm{f}$ & $54.50 \mathrm{f}$ \\
\hline $\mathrm{O} 23$ & 86.50 bc & $52.65 \mathrm{a}$ & $41.55 \mathrm{a}$ & $6.75 \mathrm{a}$ & $59.85 \mathrm{~h}$ \\
\hline P512 & $117.50 \mathrm{f}$ & $57.00 \mathrm{c}$ & 44.45 bc & $8.35 \mathrm{c}$ & $59.95 \mathrm{~h}$ \\
\hline F518 & 85.50 bc & 53.45 a & $43.15 b$ & $10.55 \mathrm{fg}$ & $62.05 \mathrm{i}$ \\
\hline Y25 & $84.00 \mathrm{~b}$ & $54.90 \mathrm{~b}$ & 44.65 bc & 9.40 de & $56.85 \mathrm{~g}$ \\
\hline P223 & 87.00 bc & $60.25 \mathrm{e}$ & $56.80 \mathrm{~h}$ & 10.0 ef & $55.55 \mathrm{fg}$ \\
\hline F210 & $107.0 \mathrm{e}$ & $63.15 \mathrm{f}$ & $54.30 \mathrm{~g}$ & $9.05 \mathrm{~d}$ & $54.90 \mathrm{f}$ \\
\hline Ellendale & $129.4 \mathrm{~g}$ & $66.90 \mathrm{~g}$ & $51.65 \mathrm{f}$ & $7.53 \mathrm{~b}$ & $59.67 \mathrm{~h}$ \\
\hline Fortune & $96.37 \mathrm{~d}$ & 60.03 e & $47.50 \mathrm{~d}$ & $6.60 \mathrm{a}$ & $55.60 \mathrm{fg}$ \\
\hline Murcott & $94.00 \mathrm{~d}$ & $59.00 \mathrm{~d}$ & $45.75 \mathrm{c}$ & 9.35 de & $51.00 \mathrm{e}$ \\
\hline Murta & $88.25 \mathrm{c}$ & $59.00 \mathrm{~d}$ & $45.25 \mathrm{c}$ & $7.50 \mathrm{~b}$ & $48.50 \mathrm{~d}$ \\
\hline
\end{tabular}

${ }^{1}$ Data are expressed as mean $(n=3-9)$; different letters in the same column, indicate significant differences $(p<0.05)$. 
Table 2. Vitamin C $\left(\mathrm{mg} \cdot 100 \cdot \mathrm{mL}^{-1}\right)$, TAA $\left(\mathrm{mg} \cdot 100 \cdot \mathrm{mL}^{-1}\right)$, Flavonoids $\left(\mathrm{mg} \cdot 100 \cdot \mathrm{mL}^{-1}\right)$ and Carotenoids $\left(\mathrm{mg} \cdot \mathrm{L}^{-1}\right)$, in $\mathrm{mandar}-$ ins studied ${ }^{1}$.

\begin{tabular}{cccccccccc}
\hline Names & Vit. C & TAA $^{3}$ & Ratio $^{4}$ & Narirutin & Hesperidin & Didymin $^{\beta}$ & $\beta$-Cryp & $\beta_{\text {-Car }}{ }^{5}$ & Vit. $^{6}$ \\
\hline Arrufatina & $59.30 \mathrm{~m}$ & $66.92 \mathrm{~g}$ & $1.13 \mathrm{a}$ & $5.40 \mathrm{f}$ & $12.94 \mathrm{~b}$ & $0.67 \mathrm{abc}$ & $10.54 \mathrm{e}$ & $0.103 \mathrm{abc}$ & 895 \\
Fina & $47.26 \mathrm{l}$ & $57.24 \mathrm{ef}$ & $1.21 \mathrm{ab}$ & $1.96 \mathrm{abc}$ & $14.17 \mathrm{bcd}$ & $0.53 \mathrm{a}$ & $14.23 \mathrm{~h}$ & $0.102 \mathrm{abc}$ & 1203 \\
Loretina & $48.77 \mathrm{l}$ & $67.11 \mathrm{~g}$ & $1.38 \mathrm{bc}$ & $2.05 \mathrm{abc}$ & $13.93 \mathrm{bc}$ & $0.55 \mathrm{ab}$ & $10.73 \mathrm{e}$ & $0.103 \mathrm{abc}$ & 911 \\
Moncada & $23.51 \mathrm{bc}$ & $37.87 \mathrm{ab}$ & $1.61 \mathrm{def}$ & $1.72 \mathrm{ab}$ & $14.19 \mathrm{bcd}$ & $0.53 \mathrm{a}$ & $2.72 \mathrm{a}$ & $0.112 \mathrm{c}$ & 245 \\
Moncalina & $22.06 \mathrm{ab}$ & $36.46 \mathrm{a}$ & $1.66 \mathrm{ef}$ & $1.62 \mathrm{ab}$ & $15.13 \mathrm{~cd}$ & $0.55 \mathrm{ab}$ & $3.59 \mathrm{~b}$ & $0.139 \mathrm{~d}$ & 322 \\
O23 & $26.90 \mathrm{de}$ & $44.03 \mathrm{~d}$ & $1.64 \mathrm{def}$ & $3.05 \mathrm{~cd}$ & $19.01 \mathrm{e}$ & $1.16 \mathrm{ef}$ & $3.04 \mathrm{ab}$ & $0.159 \mathrm{de}$ & 280 \\
P512 & $29.11 \mathrm{ef}$ & $42.45 \mathrm{~cd}$ & $1.46 \mathrm{~cd}$ & $5.01 \mathrm{ef}$ & $20.55 \mathrm{ef}$ & $1.29 \mathrm{f}$ & $2.99 \mathrm{ab}$ & $0.217 \mathrm{~g}$ & 285 \\
F518 & $32.78 \mathrm{gh}$ & $54.25 \mathrm{e}$ & $1.65 \mathrm{def}$ & $3.76 \mathrm{de}$ & $19.92 \mathrm{ef}$ & $1.15 \mathrm{ef}$ & $2.63 \mathrm{a}$ & $0.176 \mathrm{ef}$ & 248 \\
Y25 & $36.73 \mathrm{ij}$ & $57.59 \mathrm{ef}$ & $1.57 \mathrm{cdef}$ & $15.57 \mathrm{k}$ & $24.08 \mathrm{hi}$ & $0.92 \mathrm{cde}$ & $3.11 \mathrm{ab}$ & $0.185 \mathrm{f}$ & 290 \\
P223 & $39.55 \mathrm{jk}$ & $69.57 \mathrm{~g}$ & $1.76 \mathrm{fg}$ & $12.95 \mathrm{ij}$ & $25.55 \mathrm{i}$ & $0.79 \mathrm{bcd}$ & $3.08 \mathrm{ab}$ & $0.098 \mathrm{abc}$ & 273 \\
F210 & $39.97 \mathrm{k}$ & $67.99 \mathrm{~g}$ & $1.70 \mathrm{fg}$ & $11.63 \mathrm{i}$ & $23.97 \mathrm{ghi}$ & $0.75 \mathrm{abc}$ & $2.92 \mathrm{ab}$ & $0.109 \mathrm{c}$ & 261 \\
Ellendale & $40.77 \mathrm{k}$ & $67.28 \mathrm{~g}$ & $1.65 \mathrm{def}$ & $8.81 \mathrm{~h}$ & $21.72 \mathrm{fg}$ & $2.92 \mathrm{hi}$ & $13.13 \mathrm{~g}$ & $0.108 \mathrm{bc}$ & 1112 \\
Fortune & $19.57 \mathrm{a}$ & $41.74 \mathrm{bcd}$ & $2.13 \mathrm{~h}$ & $6.90 \mathrm{~g}$ & $22.00 \mathrm{fgh}$ & $3.12 \mathrm{i}$ & $10.36 \mathrm{e}$ & $0.098 \mathrm{abc}$ & 880 \\
Murcott & $22.12 \mathrm{ab}$ & $38.40 \mathrm{abc}$ & $1.74 \mathrm{fg}$ & $12.65 \mathrm{i}$ & $6.65 \mathrm{a}$ & $2.57 \mathrm{~g}$ & $11.55 \mathrm{f}$ & $0.377 \mathrm{i}$ & 1025 \\
Murta & $25.66 \mathrm{~cd}$ & $41.74 \mathrm{~cd}$ & $1.63 \mathrm{def}$ & $14.04 \mathrm{j}$ & $7.26 \mathrm{a}$ & $2.86 \mathrm{~h}$ & $8.43 \mathrm{~d}$ & $0.284 \mathrm{~h}$ & 750 \\
\hline
\end{tabular}

${ }^{1}$ Data are expressed as mean $(n=3-9)$; different letters in the same column, indicate significant differences ( $\left.p<0.05\right)$; ${ }^{2}$ As vitamin $C$ total determined by the HPLC method; ${ }^{3}$ Total antioxidant activity from the hydrophilic fraction expressed as L-ASC equivalent determined by the ABTS method; ${ }^{4}$ TAA/Vit C total. ${ }^{5} \beta$-cryp $=\beta$-cryptoxanthin, and $\beta$-car $=\beta$-carotene; ${ }^{6}$ Value expressed as retinol equivalents $\mathrm{L}^{-1}$.

Table 3. Organic acids and Carbohydrates $\left(\mathrm{g} \cdot \mathrm{L}^{-1}\right)$ in mandarins studied ${ }^{1}$.

\begin{tabular}{|c|c|c|c|c|c|c|}
\hline Names & Citric & Malic & Succinic & Fructose & Glucose & Sucrose \\
\hline Arrufatina & 8.97 abc & 8.14 ef & $1.47 \mathrm{c}$ & $10.49 \mathrm{ab}$ & $10.71 \mathrm{ab}$ & 59.18 c \\
\hline Fina & $6.68 \mathrm{a}$ & 9.13 gh & $0.69 \mathrm{a}$ & $15.81 \mathrm{~cd}$ & 12.89 abc & $64.88 \mathrm{~cd}$ \\
\hline Loretina & $8.04 \mathrm{ab}$ & $7.39 \mathrm{e}$ & $0.71 \mathrm{a}$ & $14.40 \mathrm{abc}$ & 13.19 abc & 52.42 bc \\
\hline Moncada & $9.01 \mathrm{abc}$ & $8.76 \mathrm{fg}$ & 2.74 efg & $25.03 \mathrm{f}$ & 20.93 de & 75.90 de \\
\hline Moncalina & 9.86 bcd & $8.90 \mathrm{fg}$ & 2.72 efg & $24.85 \mathrm{f}$ & $19.94 \mathrm{~d}$ & 77.32 de \\
\hline $\mathrm{O} 23$ & 10.00 bcd & $8.85 \mathrm{fg}$ & 2.74 efg & $35.82 \mathrm{~g}$ & $28.40 \mathrm{fg}$ & $43.66 \mathrm{ab}$ \\
\hline P512 & 10.77 cde & $9.22 \mathrm{gh}$ & $3.07 \mathrm{~h}$ & $27.61 \mathrm{f}$ & 21.12 de & 53.35 bc \\
\hline F518 & 11.22 cdef & $8.85 \mathrm{fg}$ & $2.96 \mathrm{gh}$ & $33.28 \mathrm{~g}$ & 25.64 ef & 59.55 c \\
\hline Y25 & $12.03 \mathrm{def}$ & $9.93 \mathrm{~h}$ & $3.59 \mathrm{i}$ & $17.61 \mathrm{~cd}$ & 13.49 abc & 82.65 ef \\
\hline P223 & 13.35 ef & $11.20 \mathrm{i}$ & $2.96 \mathrm{gh}$ & 23.76 ef & $16.69 \mathrm{~cd}$ & $95.91 \mathrm{fg}$ \\
\hline F210 & $13.52 \mathrm{f}$ & $12.75 \mathrm{j}$ & $2.92 \mathrm{gh}$ & 19.99 de & $14.22 \mathrm{abc}$ & 75.31 de \\
\hline Ellendale & $26.54 \mathrm{j}$ & $7.70 \mathrm{e}$ & $1.12 \mathrm{~b}$ & $15.13 \mathrm{bcd}$ & 13.69 abc & $59.01 \mathrm{c}$ \\
\hline Fortune & $21.08 \mathrm{hi}$ & $5.35 \mathrm{~cd}$ & $2.85 \mathrm{gh}$ & $14.97 \mathrm{bcd}$ & 13.79 abc & 55.02 bc \\
\hline Murcott & $19.44 \mathrm{~h}$ & 4.96 bcd & 2.57 ef & $33.67 \mathrm{~g}$ & $30.69 \mathrm{gh}$ & $96.18 \mathrm{~g}$ \\
\hline Murta & $16.39 \mathrm{~g}$ & 4.56 abc & $2.49 \mathrm{e}$ & $36.25 \mathrm{~g}$ & $34.67 \mathrm{~h}$ & $111.24 \mathrm{~h}$ \\
\hline
\end{tabular}

${ }^{1}$ Data are expressed as mean $(n=3-9)$; different letters in the same column, indicate significant differences $(p<0.05)$.

with those reported in the literature for different citrus varieties [4]. Clementine mandarins Arrufatina, Loretina and Fina displayed the highest values of total vitamin C, followed by the hybrid Ellendale, while Fortune, 
Moncalina and Murcott presented the lowest values (Table 2).

Regarding antioxidant activity, the most widely used methods for measuring it are those that involve the generation of radical species; presence of antioxidant determines the disappearance of these radicals. The DPPH, ABTS, FRAP and oxygen radical absorbance capacity (ORAC) assays are the most widely used methods for determining antioxidant capacity in vitro [27]. We used herein an end-point method for estimating TAA from the aqueous phase, which is easy and rapid to perform, and the correlation between ascorbic acid and antioxidant activity was also examined. The ABTS radical can be generated by the enzymatic system formed by hydrogen peroxide and horseradish peroxidase. Based on these considerations, Cano et al. [19] developed a spectrophotometric end-point method to evaluate ascorbic acid in aqueous media under optimal conditions of temperature, $\mathrm{pH}$ and reagent concentration. Significant differences were observed among the juices of the different tested varieties. Fortune and Moncada/Murcott series, showed the lowest antioxidant activity value. These values can be related to the lower vitamin C level exhibited by the Fortune and Moncada/Murcott series when compared with the other studied varieties. New varieties P223 and F210 displayed the highest TAA values $\left(69.57 \mathrm{mg} \cdot 100 \mathrm{~mL}^{-1}\right.$ and $67.99 \mathrm{mg} \cdot 100 \mathrm{~mL}^{-1}$, respectively). In all cases, the TAA of the hydrophilic fraction was higher than the absolute contribution of the analyzed ascorbic acid (Table 2).

\subsection{Flavonoids Content}

In general, flavonoids may contribute to fruit and juice quality in many ways, which influences their appearance, taste and nutritional value. Flavonoids are widely distributed in fruits and each species is characterized by a particular flavanone glycoside pattern [7] [9] [28]. Flavanones are major flavonoids in citrus fruits and we have observed that the evaluated cultivars did not differ in terms of the individual flavonoid chromatographic profiles. Except Murcott and Murta, as shown in Table 2, the most abundant flavanone glycoside identified in mandarins and hybrids juice was hesperidin, which was detected at the highest concentrations, followed by narirutin and didymin. The amounts of hesperidin varied between 25.75 and $12.94 \mathrm{mg} \cdot 100 \mathrm{~mL}^{-1}$, and these values agree with those reported in the literature for other citrus varieties. Regarding level of naritutin, recent studies have shown a naritutin content above that of hesperidin in citrus varieties Murcott tangor and in Mineola tangelo. Murcott and Murta fruit juices gave high narirutin values (12.65 and $14.04 \mathrm{mg} \cdot 100 \mathrm{~mL}^{-1}$, respectively), while Y25 and new varieties P223 and F210 also displayed high narirutin content (11.63 to $15.57 \mathrm{mg} \cdot 100 \mathrm{~mL}^{-1}$ ). For didymin levels, the values shown in all the studied varieties agree with previous studies into tangor and mandarin fruits [18] [21] [29].

\subsection{Carotenoids Content}

The peel and pulp of citrus fruits are an important source of carotenoids, and thus of natural pigments; in juices, the most abundant ones are $\beta$-carotene, $\beta$-cryptoxanthin, lutein and zeaxanthin, all of which have antioxidant activity. The vitamin A value was calculated as the retinol equivalent (RE) according to Dhuique-Mayer et al. [9]. Previous results in mandarin species have indicated in most varieties that clementines present larger amounts of $\beta$-cryptoxanthin as the most abundant nutritional carotenoid and low concentrations of $\beta$-carotene in all the citrus cultivars studied [22]. Our results coincide with this previously reported citrus study, and we identified and quantified $\beta$-cryptoxanthin and $\beta$-carotene from the saponified extracts of the juices of all the citrus cultivars studied (Table 2). In addition, violaxanthin and zeaxanthin were identified tentatively based on retention times and absorption spectrum characteristics with the corresponding authentic standards (data not reported). The $\beta$-Carotene values ranged from 0.082 to $0.377 \mathrm{mg} \cdot \mathrm{L}^{-1}$ of juice from the saponified extracts of the juices, whereas all the studied citrus cultivars presented larger amounts of $\beta$-cryptoxanthin (between 2.63 and $14.23 \mathrm{mg} \cdot \mathrm{L}^{-1} \mathrm{of}$ juice), with Fina, Ellendale and Murcott being especially rich in this main provitamin A carotenoid (Table 2).

\subsection{Organic Acids and Carbohydrates Content}

The ratio between sugars and organic acids upon consumption maturity is a common quality index and a good indicator of internal fruit quality. The main organic acids of citrus fruits are citric and malic acids. Traces of benzoic, oxalic and succinic acids have also been reported [5] [6] [30]. Herein the organic acid profile was determined and three acids were quantified (Table 3). Ellendale exhibited the highest levels of citric acid (26.54 $\mathrm{g} \cdot \mathrm{L}^{-1}$ ), followed by Fortune and Murcott. The remaining values ranged from 6.68 to $16.39 \mathrm{~g} \cdot \mathrm{L}^{-1}$, similarly to those reported previously [4] [23]. Sugar composition was determined and three sugars were quantified in all the 
arieties studied (Table 3). Sugars are major components of citrus juice soluble solids and sweetness of citrus juice is intrinsic to its sugar composition. The predominant sugar found was sucrose, which is in agreement with the literature, followed by fructose and glucose [6] [30]. Murta and Murcott fruit juices gave the highest levels of sucrose (111.24 and $96.18 \mathrm{~g} \cdot \mathrm{L}^{-1}$ ), followed by Y25, P223 and F210. The remaining sucrose values ranged from 34.63 to $77.32 \mathrm{~g} \cdot \mathrm{L}^{-1}$. The fructose:glucose:sucrose ratio (1:1:2) was similar for all the cultivars under study, and sucrose was present in all the cultivars in the largest amounts.

\subsection{Principal Component Analysis and Clustering}

Through a correlation by a multivariate discriminant analysis, the 15 citrus cultivars were clustered into four groups consistently with citrus types. The PCA separated samples according to the composition of bioactive compounds and antioxidant activity, which supported the formation of four groups. The PCA analysis results are shown in Figure 1(a), where groupings are suggested. It is apparent that clementines (Arrufatina, Fina, Loretina)

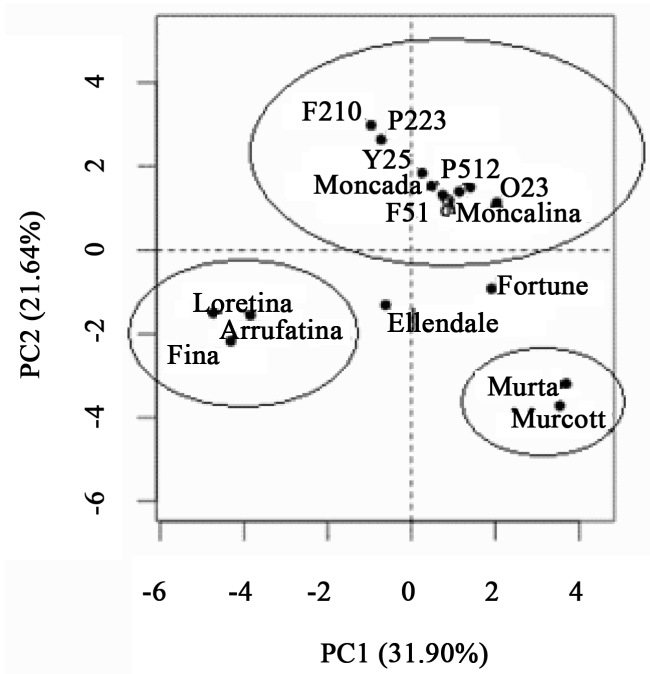

(a)

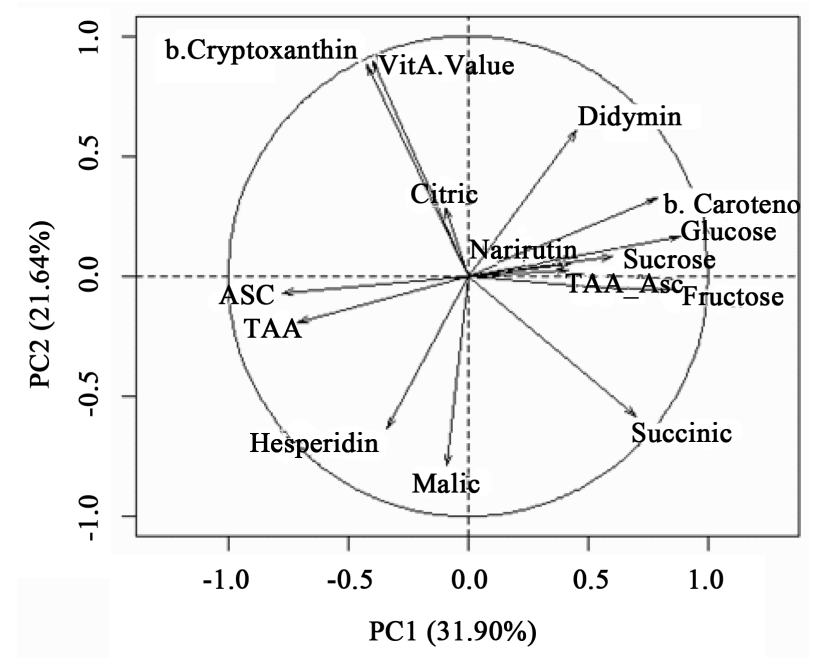

(b)

Figure 1. Bi-plot of principal component 2 and principal component 1 for the different mandarins studied: (a) Individual factor map: differentiation of citrus using PCA, arbitrary groups are represented by ellipses; (b) Variables factor map: factor loading for principal component. 


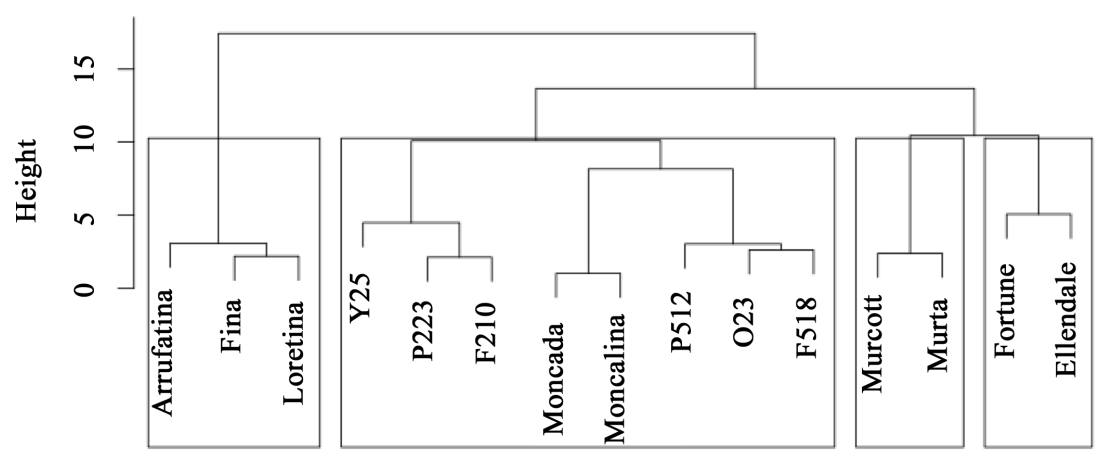

Figure 2. Dendogram of the cluster analysis for the different mandarins studied.

formed a single group. A second group was formed by hybrids Murcott and Murta. Clementine hybrids (Y25, P223, F210, Moncada, Moncalina, O23, P512 and F518) formed a third group. Fortune and Ellendale appeared outside, formed the fourth group. Regarding the correlation between variables (Figure 1(b)), the first principal component (PC1) (31.90\% of variance) correlated mainly with content of sugars (positively) and antioxidants (negatively), while the second component (PC2, 21.64\% of variablility) correlated positively with the vitamin A value and $\beta$-cryptoxanthin. The CA analysis results (Figure 2) correlated very well with the PCA analysis: clementines, clementine hybrids, hybrids Murcott and Murta; and Fortune and Ellendale appeared outside, formed the fourth group.

\section{Conclusion}

The results of this study encourage us to continue investigations in new mandarin cultivars with different pollination, seed production and parthenocarpic abilities. Regarding flavonoids and vitamin C content, some cultivars presented high contents of both these antioxidants, of which Y25, P223 and F210 are stressed, and obtained higher TAA values. Major differences must be attributed mainly to genetic factors. We found clear differences in the main nutritional components and in antioxidant activity for the different groups, as suggested by the PCA and CA analyses, which agrees with the Citrus classification, with a few exceptions. The data presented herein are an important factor to help choose varieties with high potential as a nutraceutical source. These aspects are necessary as consumers demand the prevention of health problems through nutrition and certain fruit quality traits, which include fruit size, internal quality, good rind color and easy peeling.

\section{Acknowledgements}

This work has been supported by RTA2011-00052-00-00 and RTA2013-00043-C02-01 from INIA (Spain), and by the Consellería de Agricultura, Pesca y Alimentación (Valencia, Spain).

\section{References}

[1] Abeysinghe, D.C., Li, X., Sun, C.D., Zhang, W.S., Zhou, C.H. and Chen, K.S. (2007) Bioactive Compounds and Antioxidant Capacities in Different Edible Tissues of Citrus Fruit of Four Species. Food Chemistry, 104, 1338-1344. http://dx.doi.org/10.1016/j.foodchem.2007.01.047

[2] Genovese, S., Fiorito, S., Locatelli, M., Carlucci, G. and Epifano, F. (2014) Analysis of Biologically Active Oxyprenylated Ferulic Acid Derivatives in Citrus Fruits. Plant Foods for Human Nutrition, 69, 255-260. http://dx.doi.org/10.1007/s11130-014-0427-8

[3] Goulas, V. and Manganaris, G.A. (2012) Exploring the Phytochemical Content and the Antioxidant Potential of Citrus Fruits Grown in Cyprus. Food Chemistry, 131, 39-47. http://dx.doi.org/10.1016/j.foodchem.2011.08.007

[4] Carballo, S., Zingarello, F.Z., Maestre, S.E., Todolí, J.L. and Trats, M.S. (2014) Optimisation of Analytical Methods for the Characterization of Orangesm Clementines and Citrus Hybrids Cultivated in Spain on the Basis of Their Composition in Ascorbic Acid, Citric Acid and Major Sugars. International Journal of Food Science \& Technology, 49, 146-152. http://dx.doi.org/10.1111/ijfs.12289

[5] Albertini, M.B., Carcouet, E., Pailly, O., Gambotti, C., Luro, F. and Berti, L. (2006) Changes in Organic Acids and Sugars during Early Stages of Development of Acidic and Acidless Citrus Fruit. Journal of Agricultural and Food 
Chemistry, 54, 8335-8339. http://dx.doi.org/10.1021/jf061648j

[6] Kelebek, H. and Selli, S. (2011) Determination of Volatile, Phenolic, Organic Acid and Sugar Components in a Turkish cv. Dortyol (Citrus sinensis L. Osbeck) Orange Juice. Journal of the Science of Food and Agriculture, 91, 18551862. http://dx.doi.org/10.1002/jsfa.4396

[7] Nogata, Y., Sakamoto, K., Shiratsuchi, H., Ishii, T., Yano, M. and Ohta, H. (2006) Flavonoid Composition of Fruit Tissues of Citrus Species. Bioscience, Biotechnology and Biochemistry, 70, 178-192. http://dx.doi.org/10.1271/bbb.70.178

[8] Tanaka, T. (1969) Misunderstanding with Regards Citrus Classification and Nomenclature. Bulletin of the University of Osaka Prefecture Series B, 21, 139-145.

[9] Dhuique-Mayer, C., Caris-Veyrat, C., Ollitrault, P., Curck, F. and Amiot, M.J. (2005) Varietal and Interspecific Influence on Micronutrient Contents in Citrus from the Mediterranean Area. Journal of Agricultural and Food Chemistry, 53, 2140-2145. http://dx.doi.org/10.1021/jf0402983

[10] Lee, SK. and Kader, A.A. (2000) Preharvest and Postharvest Factors Influencing Vitamin C Content of Horticultural crops. POSTHARVEST Biology and Technology, 20, 207-220. http://dx.doi.org/10.1016/s0925-5214(00)00133-2

[11] Goldenberg, L., Yaniv, Y., Kaplunov, T., Doron-Faigenboim, A., Carmi, N. and Porat, R. (2014) Genetic Diversity among Mandarins in Fruit-Quality Traits. Journal of Agricultural and Food Chemistry, 62, 4938-4946. http://dx.doi.org/10.1021/jf5002414

[12] Goldenberg, L., Yaniv, Y., Kaplunov, T., Doron-Faigenboim, A., Porat, R. and Carmi, N. (2015) Diversity in Sensory Quality and Determining Factors Influencing Mandarin Flavor Liking. Journal of Food Science, 80, S418-S425. http://dx.doi.org/10.1111/1750-3841.12742

[13] Vardi, A., Levin, I. and Carmi, N. (2008) Induction of Seedlessness in Citrus: From Classical Techniques to Emerging Biotechnological Approaches. Journal of the American Society for Horticultural Science, 133, 117-126. http://journal.ashspublications.org/content/133/1/117.full.pdf+html

[14] Bermejo, A., Pardo, J. and Cano, A. (2011) Influence of Gamma Irradiation on Seedless Citrus Production: Pollen Germination and Fruit Quality. Food and Nutrition Sciences, 2, 169-180. http://dx.doi.org/10.4236/fns.2011.23024

[15] Bermejo, A., Pardo, J. and Cano, A. (2012) Murcott Seedless: Influence of Gamma Irradiation on Citrus Production and Fruit Quality. Spanish Journal of Agricultural Research, 10, 768-777. http://dx.doi.org/10.5424/sjar/2012103-460-11

[16] Bermejo, A., Pardo, J. and Zaragoza S. (2015) Influence of Gamma Irradiation on Seedless Citrus Production: Pollen Germination and Fruit Quality. Acta Horticulturae (ISHS), 1065, 229-237. http://www.actahort.org/members/showpdf?booknrarnr=1065_25 http://dx.doi.org/10.17660/ActaHortic.2015.1065.25

[17] Bermejo, A., Primo-Millo, E., Agustí, M., Mesejo, C., Reig, C. and Iglésias, D.J. (2015) Hormonal Profile in Ovaries of Mandarin Varieties with Differing Reproductive Behaviour. Journal of Plant Growth Regulation, 34, 584-594. http://dx.doi.org/10.1007/s00344-015-9492-y

[18] Sdiri, S., Bermejo, A., Aleza, P., Navarro, P. and Salvador, A. (2012) Phenolic composition, organic acids, sugars, vitamin $\mathrm{C}$ and antioxidant activity in the juice of new triploid late-season mandarins. Food Research International, 49, 462-468. http://dx.doi.org/10.1016/j.foodres.2012.07.040

[19] Cano, A., Hernández-Ruíz, J., García-Cánovas, F., Acosta, M. and Arnao, M.B. (1998) An End-Point Method for Estimation of the Total Antioxidant Activity in Plant Material. Phytochemical Analysis, 9, 196-202. http://dx.doi.org/10.1002/(SICI)1099-1565(199807/08)9:4<196::AID-PCA395>3.0.CO;2-W

[20] Arnao, M.B., Cano, A. and Acosta, M. (2001) The Hydrphilic and Lipophilic Contribution to Total Antioxidant Activity. Food Chemistry, 73, 239-244. http://dx.doi.org/10.1016/S0308-8146(00)00324-1

[21] Cano, A., Medina, A. and Bermejo, A. (2008) Bioactive Compounds in Different Citrus Varieties. Discrimination among Cultivars. Journal of Food Composition and Analysis, 21, 377-381. http://dx.doi.org/10.1016/j.jfca.2008.03.005

[22] Cano, A. and Bermejo, A. (2011) Influence of Rootstock and Cultivar on Bioactive Compounds in Citrus Peels. Journal of the Science of Food and Agriculture, 91, 1702-1711. http://dx.doi.org/10.1002/jsfa.4375

[23] Bermejo, A. and Cano, A. (2012) Analysis of Nutritional Constituents in Twenty Citrus Cultivars from the Mediterranean Area at Different Stages of Ripening. Food and Nutrition Sciences, 3, 639-650. http://dx.doi.org/10.4236/fns.2012.35088

[24] Team, R.C. (2013) A Language and Environment for Statistical Computing. R Foundation for Statistical Computing, Vienna, Austria. http://www.R-project.org

[25] Husson, F., Josse, J., Le, S. and Mazet, J. (2014) FactoMineR: Multivariate Exploratory Data Analysis and Data Mining with R. R Package Version 1.28. http://CRAN.R-project.org/package=FactoMineR 
[26] Oksanen, J., Blanchet, F.G., Kindt, R., Legendre, P., Minchin, P.R., O’Hara, R.B., Simpson, G.L., Solymos, P., Stevens, M.H.H. and Wagner, H. (2014) Vegan: Community Ecology Package. R Package Version 2.2-0. http://CRAN.Rproject.org/package=vegan

[27] Xu, H.X. and Chen, J.W. (2010) Commercial Quality, Major Bioactive Compound Content and Antioxidant Capacity of 12 Cultivars of Loquat (Eriobotrya japonica Lindl.) Fruits. Journal of the Science of Food and Agriculture, 91, 1057-1063. http://dx.doi.org/10.1002/jsfa.4282

[28] Yao, L.H., Jiang, Y.M., Tomás-Barberán, F.A., Datta, N., Singanusong, R. and Chen, S.S. (2004) Flavonoids in Food and Their Health Benefits. Plant Foods for Human Nutrition, 59, 113-122. http://dx.doi.org/10.1007/s11130-004-0049-7

[29] Ramful, D., Tarnus, E., Aruoma, O.I, Bourdon, E. and Bahroun, T. (2011) Polyphenol Composition, Vitamin C Content and Antioxidant Capacity of Mauritian Citrus Fruit Pulps. Food Research International, 44, 2088-2099. http://dx.doi.org/10.1016/j.foodres.2011.03.056

[30] Roussos, P.A. (2011) Phytochemicals and Antioxidant Capacity of Orange (Citrus sinensis (L.) Osbeck cv. Salustiana) Juice Produced under Organic and Integrated Farming System in Greece. Scientia Horticulturae, 129, 253-258. http://dx.doi.org/10.1016/j.scienta.2011.03.040 